\title{
Fatores que interferem na qualidade de vida de mães adolescentes após o nascimento do bebê
}

\author{
Factores that interfere with the quality of life of teenage mothers after the baby is \\ born
}

\author{
Valderice Vasques Pereira ${ }^{1 *}$, Larysa de Col Dalazoana Baier ${ }^{2}$, Ana Paula Xavier Ravelli ${ }^{3}$, \\ Suellen Viencoski ${ }^{4}$,Ianka do Amaral ${ }^{5}$
}

\begin{abstract}
RESUMO
Trata-se de um estudo quantitativo, no qual os dados são descritos por critérios matemáticos e técnicas estatísticas. O objetivo da pesquisa foi conhecer a realidade de vida das mães adolescentes após o nascimento de seu filho, buscando entender como está a qualidade de vida destas puérperas. A pesquisa foi realizada através de questionário semi-estruturado, enviados via aplicativo whatsapp por meio de perguntas fechadas e abertas. As participantes da pesquisa foram as puérperas atendidas pelo Projeto CEPP (Consulta de Enfermagem no Pré-Natal e Pós-Parto) do Hospital Universitário Regional de Ponta Grossa atendidas nos anos de 2019 e 2020. A partir da pesquisa realizada através do questionário, foi possível visualizar as mudanças ocasionadas na vida da adolescente que ocorreram desde a gestação e continuam em constante mudança após o nascimento do bebê. Este estudo contribui com resultados relevantes sobre o conhecimento social e pessoal das puérperas no período da adolescência, podendo contribuir com estudos futuros que abordem o tema ou população selecionada.
\end{abstract}

Palavras-chave: Gravidez na adolecência; Adolescentes; Maternidade; Puérperio;

\begin{abstract}
This is a quantitative study, in which data are described by mathematical criteria and statistical techniques. The objective of the research was to know the reality of life of teenage mothers after the birth of their child, seeking to understand the quality of life of these mothers. The research was conducted through a semistructured questionnaire, sent via whatsapp application through closed and open questions. The research participants were postpartum women assisted by the CEPP Project (Nursing Consultation in Prenatal and Postpartum) of the Regional University Hospital of Ponta Grossa attended in 2019 and 2020. From the survey conducted through the questionnaire, it was possible visualize the changes brought about in the adolescent's life that have occurred since pregnancy and continue to change after the baby is born. This study contributes with relevant results on the social and personal knowledge of postpartum women during adolescence, and may contribute to future studies that address the topic or selected population.
\end{abstract}

\footnotetext{
${ }^{1}$ Universidade Estadual de Ponta Grossa

*E-mail: laryssadalazoana@yahoo.com.br
} 
Keywords: Pregnancy in adolescence; Teenagers; Maternity; Postpartum;

\section{INTRODUÇÃO}

A adolescência é uma fase do ciclo de vida definida pela idade dos 10 aos 19 anos, 11 meses e 29 dias, onde o adolescente busca descobrir muitas questões relacionadas às condições da sua própria identidade, procurando sanar as dúvidas frequentes sobre as mudanças que ocorrem, inclusive sobre a sexualidade e quando se busca novas experiências pode se deparar com uma gestação precoce (DUARTE; PAMPLONA; RODRIGUES, 2018).

A gravidez na adolescência é considerada um problema de saúde pública, prejudicando também a vida social da adolescente, pois são muitos conflitos que se situam neessa fase, o que leva à modificação no estilo de vida, trazendo medo e preocupações com o futuro (LEITÃO; BENEVIDES, 2016).

A gestante adolescente poderá vivenciar essa fase de diferentes formas, considerando a subjetividade de cada uma e da sua inserção social e cultural. Portanto, quando apoiada, incentivada e orientada podem conciliar a maternidade com a rotina escolar, a saúde e a própria adolescência (CREMONESE et al., 2019).

No Brasil, a partir dos anos de 1960 segundo Heilborn et al., 2002 e Santos et al., 2016, em seus estudos verificaram o aumento do uso de contraceptivo e redução no número de filhos por mulheres até 1990. Entretanto, observou-se que a taxa de fecundidade entre as adolescentes aumentou e houve uma redução nas demais faixas etárias. A partir de 2012, ainda que observado a redução da taxa de fecundidade das adolescentes, os índices ainda mantinham-se altos. Segundo dados do IBGE desse período, 10,5\% das adolescentes na faixa etária de 10 a 19 anos já tinham pelo menos um nascido vivo (SANTOS; GUIMARÃES; GAMA, 2016).

A taxa de fecundidade funciona como um indicador de qualidade de vida nos países, quanto menos desenvolvido o país, maior é o valor desse indicador, refletindo a precariedade da educação e de atenção e assistência à saúde dessa população (SANTOS; GUIMARÃES; GAMA, 2016).

Portanto, percebe-se que as ações voltadas aos adolescentes ainda são falhas e fragmentadas, não suprindo a demanda e contribuindo com a insegurança desses 
adolescentes. Deste modo, observa-se o despreparo do profissional da saúde no acolhimento ao adolescente na rede de atenção e a falta do fortalecimento de saúde da mulher no período puerperal, visto que essas adolescentes só retornam para os cuidados com a vacinação e acompanhamento do desenvolvimento do bebê (CREMONESE et al., 2019).

Deve-se considerar o papel do Enfermeiro, pois quando bem preparado promove a educação em saúde de maneira responsável, sendo capaz de esclarecer dúvidas sobre o puerpério, bem como preparar esta mãe adolescente para as novidades inerentes à maternidade, tais como os cuidados com o recém-nascido e aleitamento materno (ANDRADE et al., 2020).

Sobre o assunto estudado, surge a seguinte questão: Quais fatores interferem na qualidade de vida de mães adolescentes após o nascimento do bebê? Assim, o objetivo da pesquisa foi conhecer a realidade de vida das mães adolescentes após o nascimento de seu filho, buscando entender como está a qualidade de vida destas puérperas.

\section{MÉTODO}

Trata-se de um estudo quantitativo, no qual os dados são descritos por critérios matemáticos e técnicas estatísticas. A pesquisa foi realizada através de questionário semiestruturado, via aplicativo whatsapp por meio de perguntas fechadas e abertas. $\mathrm{O}$ termo de consentimento livre esclarecido também foi enviado da mesma forma para as entrevistadas. Os aspectos éticos foram assegurados contemplando a Resolução 466/2012 e 510/2016 com o parecer do Comitê de Ética e Pesquisa (COEP) número: 3.234.262 de 29 de março de 2019 pela Universidade Estadual de Ponta Grossa.

As participantes da pesquisa foram puérperas atendidas pelo Projeto CEPP (Consulta de Enfermagem no Pré-Natal e Pós-Parto) do Hospital Universitário Regional de Ponta Grossa atendidas no ano de 2019 e 2020.

Os critérios de inclusão utilizados foram puérperas adolescentes que aceitaram participar da pesquisa entre 10 e 19 anos, 11 meses e 29 dias e os de exclusão as que não aceitaram responder o questionário ou não se enquadram na idade selecionada.

\section{RESULTADOS E DISCUSSÃO}


A partir da pesquisa realizada através do questionário, foi possível visualizar as mudanças ocasionadas na vida da adolescente que ocorreram desde a gestação e continuam em constante mudança após o nascimento do bebê.

Realizou-se perguntas que abordavam questões sobre a idade do bebê, tempo de amamentação, moradores da casa, mudança de vida após o nascimento do bebê, questões sobre os estudos, trabalho, vida social e emocional, uso de anticoncepcional, renda familiar e bem-estar no período de pós-parto.

Quadro 1- perguntas agrupadas conforme a temática

\begin{tabular}{|c|c|}
\hline Temas & Perguntas realizadas \\
\hline Amamentação & $\begin{array}{l}\text { - Quanto tempo você } \\
\text { amamentou o seu } \\
\text { bebê? }\end{array}$ \\
\hline Família & $\begin{array}{l}\text { Com quem você } \\
\text { mora atualmente? } \\
\text { É o primeiro filho? } \\
\text { Você teve auxílio } \\
\text { da família no pós- } \\
\text { parto? } \\
\text { - De quem teve } \\
\text { auxílio no pós- } \\
\text { parto? }\end{array}$ \\
\hline Estudos & $\begin{array}{ll} & \text { Você estuda? } \\
\text { Pretende continuar } \\
\text { estudando? }\end{array}$ \\
\hline $\begin{array}{l}\text { Renda familiar e } \\
\text { emprego }\end{array}$ & $\begin{array}{l}\text { Você trabalha? } \\
\text { Pretende continuar } \\
\text { trabalhando? } \\
\text { Você considera sua } \\
\text { renda familiar } \\
\text { suficiente? } \\
\text { Você recebe } \\
\text { alguma ajuda para } \\
\text { complementar a } \\
\text { renda familiar? }\end{array}$ \\
\hline $\begin{array}{ll}\text { Bem estar } & \text { e } \\
\text { qualidade } & \text { de } \\
\text { vida } & \end{array}$ & $\begin{array}{l}\text { De } 0 \text { a } 10 \text { quanto } \\
\text { sua vida mudou } \\
\text { após o nascimento } \\
\text { do seu bebê? } \\
\text { De } 0 \text { a } 10 \text {, quanto } \\
\text { você está feliz neste } \\
\text { momento? }\end{array}$ \\
\hline
\end{tabular}




\begin{tabular}{|c|c|}
\hline & $\begin{array}{l}\text { Você costuma sair } \\
\text { para se divertir? } \\
\text {. Sente falta de sair } \\
\text { para se divertir? } \\
\text {. De } 0 \text { a } 10 \text {, qual nota } \\
\text { você daria sobre o } \\
\text { seu parto? } \\
\text { Você acredita que } \\
\text { tem uma boa } \\
\text { qualidade de vida } \\
\text { após o nascimento } \\
\text { do seu bebê? }\end{array}$ \\
\hline Cuidados & 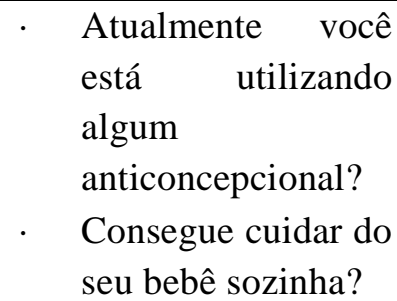 \\
\hline
\end{tabular}

\subsection{AMAMENTAÇÃO}

Fonte: dados da pesquisa, 2020.

Na primeira pergunta sobre a amamentação, questionamos por quanto tempo o bebê foi amamentado, a resposta era aberta para que pudessem responder o número de meses correspondentes quando questionadas.

A idade do bebê teve variações nas respostas sobre amamentação, conforme o quadro 2, os números mais significativos foram de 31,2\% que afirmam ainda estar em período de amamentação, $13 \%$ responderam que a amamentação ocorreu até o sexto mês e $6,25 \%$ não amamentaram. Com esses números podemos observar que $25 \%$ das entrevistadas não realizaram a amamentação pelo período recomendado, que consiste em oferecer o leite materno de maneira exclusiva até o sexto mês de vida de forma exclusiva e até os 2 anos de vida de forma complementada (CREMONESE et al., 2016).

Diante de todos os benefícios e evidências científicas comprovando a superioridade do leite materno sobre outras formas de alimentar a criança, a maioria das crianças no Brasil e no mundo não é amamentada por dois anos ou mais e não recebe leite materno exclusivo nos primeiros seis meses, como recomenda a Organização Mundial de Saúde (FERREIRA et al, 2018).

A amamentação garante proteção e diminuição das taxas de mortalidade infantil. Assim, a mortalidade por doenças infecciosas é seis vezes maior em crianças menores de 
amamentadas (BRASIL, 2015).

O apoio de sua família, sociedade e serviços de saúde, demonstram importância nesse período de intensa transformação. As orientações e incentivo nas atividades de cuidado como visitas domiciliares com agentes de saúde, consultas de pré-natal e inclusão do companheiro e familiares no período gravídico puerperal, são formas eficazes de apoios prestados à essas jovens. (CREMONESE et al., 2016).

Quadro 2- Gráfico de respostas sobre amamentação

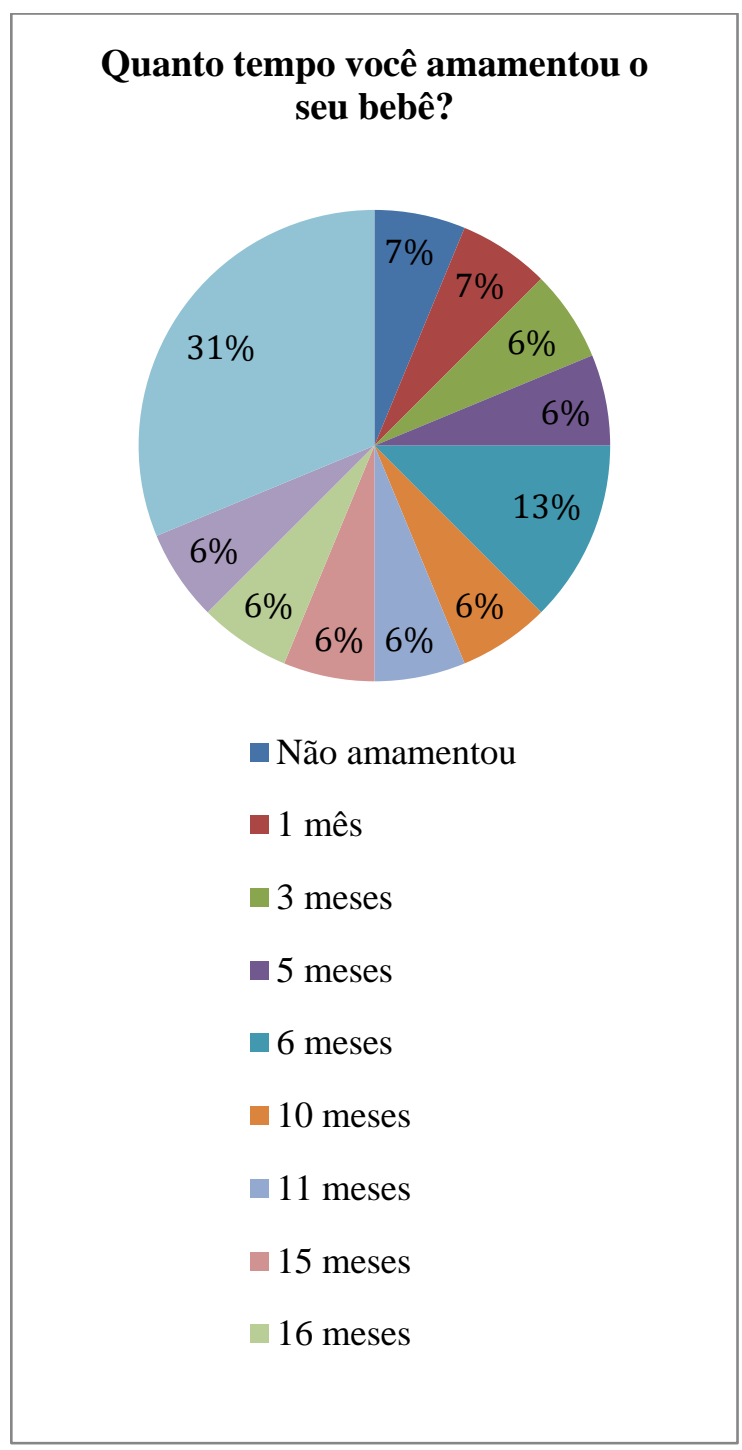

Fonte: dados da pesquisa, 2020.

3.2 FAMÍLIA

No período gestacional a mulher vivencia diferentes modificações em seu corpo e em seus sentimentos, requerendo apoio e suporte específico da família (CARPES; BIFF; STUMM, 2016). O apoio familiar pode ajudar desde aspectos 
psicológicos até cuidados diários com o bebê, facilitando essa nova fase. Foram realizadas quatro perguntas que abordavam o tema sobre a família.

Das 17 entrevistadas, 64,7\% responderam estar morando com seus companheiros, $23,5 \%$ moram com os pais e $17,6 \%$ moram sozinhas.

Sobre o auxílio familiar, $88,2 \%$ responderam ter recebido auxílio de algum familiar no período de pós-parto e 11,8\% responderam que não receberam auxilio de familiares. No estudo também obtivemos quem ajudou-a nessa fase, 58,8\% responderam ter recebido ajuda da mãe, 47,1\% receberam ajuda do companheiro, 11,8\% foram ajudadas pelos avós, 5,9\% pelo pai e $23,5 \%$ indicaram ter recebido ajuda de outras pessoas sem especificação.

O apoio familiar e a situação conjugal contribuem positivamente para adesão do aleitamento materno exclusivo. Em uma pesquisa realizada nos Estados Unidos da América com 25.197 entrevistas telefônicas nos anos de 2007 e 2008, evidenciou que crianças que vivem com os pais foram mais favoráveis ao processo de amamentação exclusiva $(80,4 \%)$ em comparação a crianças de outros tipos de famílias (FERREIRA et al., 2018).

No questionamento sobre ser o primeiro filho, $82,4 \%$ responderam ser o primeiro filho e 17,6\% responderam que já possuíam outros filhos. A experiência de gestação anterior é considerada um fator de proteção frente ao aleitamento materno. Quanto maior o número de gestações, consequentemente, maior seria a duração da amamentação para os próximos filhos. Não ter amamentado um filho anteriormente é um fator que contribui para o abandono do aleitamento materno ou desmame precoce (FERREIRA et al., 2018).

\subsection{ESTUDOS}

O afastamento da adolescente da escola não é determinado apenas pela gravidez, mas pode ser consequência do preconceito, falta de apoio e vergonha devido às mudanças corporais. A vida escolar na adolescência apresenta mudanças com a chegada do bebê, mesmo que não haja a desistência dos estudos, a rotina é alterada e isso pode trazer dificuldades de adaptação (RODRIGUES et al., 2019).

No que diz respeito ao estudo, 64,7\% responderam que ainda estudam e 35,3\% responderam que não frequentam mais a escola. Na pergunta "Se sim, pretende continuar estudando?" $71,4 \%$ responderam que sim e $28,6 \%$ responderam que não. Não teve o questionamento de por que elas não gostariam de continuar os estudos. 
No que diz respeito à escolaridade materna, a maior parte das gestantes adolescentes se afastam da escola e possuem baixo grau de instrução, possuindo uma tendência a não realizarem o aleitamento materno de forma adequada. As mães com maior escolaridade apresentam mais chance de permanência na prática do aleitamento materno exclusivo, devido ao maior suporte de pré-natal e às informações sobre as vantagens do aleitamento materno (BARROS et al., 2021).

A adolescência é um período em que os indivíduos estão em formação no âmbito escolar e muitas adolescentes possuem objetivos que podem incentivar as suas futuras escolhas profissionais e pessoais. Assumir o papel de mãe e responsável pelos cuidados com a casa, diminui a possibilidade de qualificação profissional, prejudicando sua produtividade e colocando-a em desvantagem social (MONTEIRO et al., 2011).

\subsection{RENDA FAMILIAR E EMPREGO}

Quando questionadas sobre emprego, 52,9\% indicam que não trabalham e 47,1\% afirmam ter uma fonte de renda. Se a resposta sobre o emprego foi afirmativa, foi questionado sobre a pretensão em continuar trabalhando, $42,9 \%$ responderam que não pretendem voltar ao mercado de trabalho e $57,1 \%$ responderam que tem desejo de retornar as suas atividades.

Na pergunta "Você considera sua renda familiar suficiente?", 58,8\% relatam que não consideram suficiente a renda que a família tem, 41,2\% dizem considerar a renda suficiente, 70,6\% responderam não receber ajuda para complementar a renda familiar e $29,4 \%$ responderam que recebem algum tipo de ajuda.

Alguns estudos mostram que pertencer a classes mais baixas e possuir menor renda econômica está relacionado com maiores chances de adesão a amamentação (BARROS et al., 2021).

No entanto, a falta de conhecimento de como enfrentar as dificuldades ao longo do processo do aleitamento materno, tais como a necessidade do retorno ao trabalho, ingurgitamento mamário, fissuras mamilares e não saberem se devem continuar oferecendo seu leite nessas situações, ainda são questões a serem consideradas como fator limitante para o AME entre as mulheres de baixa renda (BARROS et al., 2021).

\subsection{BEM ESTAR E QUALIDADE DE VIDA}

A qualidade de vida é definida como a percepção do indivíduo frente a cultura, os valores de vida e a relação com seus objetivos, expectativas, padrões e preocupações. 
Por tratar-se de um conceito amplo e complexo, abrange a saúde física, o estado psicológico, as relações sociais, as crenças pessoais e a interação do indivíduo com o meio ambiente (FARINHA et al., 2018; SCHUMACHER et al., 2020).

Sobre esse tema, as perguntas foram disponibilizadas em forma de classificação, com respostas que poderiam ser marcadas do número zero até o número dez.

Com relação a mudança de vida, "de 0 a 10 quanto sua vida mudou após o nascimento do seu bebê?" Recebemos a nota 10 em 64,7\% das respostas, indicando a mudança completa na vida das entrevistadas, $17,6 \%$ responderam com a nota 8 , tivemos $11,8 \%$ respostas com a nota 9 e apenas $5,9 \%$ marcaram como 5 a resposta dessa pergunta.

Sobre o "quanto você está feliz neste momento?" 52,9\% responderam com a nota 10, indicando felicidade sobre o momento de pós-parto. Com a nota 9, obtivemos 17,6\% das respostas, 23,5\% marcaram a reposta 8 como opção e 5,9\% indicaram a nota 7 .

Podemos observar através desses valores que o nível de felicidade indicado pelas entrevistadas é elevado e através dos números podemos considerar um nível satisfatório sobre esse momento na vida da adolescente (CONDELES et al., 2019).

Quando questionadas sobre a vida social, "Você costuma sair para se divertir?", $52,9 \%$ responderam que não e 47,1 deram a resposta afirmativa sobre a pergunta. "Se não, sente falta de sair para se divertir? ", apenas 15,4\% responderam que não e $84,6 \%$ responderam que sim.

Um estudo de corte transversal realizado em 2010, durante uma campanha de vacinação, foi composto de 2.259 binômios dos quais foram aplicados a Escala de Depressão Pós-Parto de Edimburgo, instrumento utilizado para o rastreamento da depressão puerperal, e um formulário com perguntas sobre características sócio demográficas da puérpera. O resultado mostrou maior prevalência da ausência da amamentação em crianças cujas mães apresentavam depressão pós-parto e início do prénatal tardio. Estas mães eram adolescentes e com fator sócio econômico de baixa renda (PEREIRA et al., 2021).

Podemos agrupar a questão sobre o parto nessa categoria, pois esse momento pode contribuir com o bem-estar e qualidade de vida da mãe. A pergunta realizada foi: De 0 a 10, qual nota você daria sobre o seu parto? 35,3\% responderam com a nota $10,23,5 \%$ deram a nota $9,17,6 \%$ marcaram a nota $8,11,8 \%$ responderam com nota 5 e foram marcadas por 5,9\% ambas as opções 6 e 7 . 
O parto traumático aparece em outros estudos como fator contribuinte para o abandono do aleitamento materno no segundo mês após o parto (PEREIRA et al., 2021).

Sobre o questionamento de ter uma boa qualidade de vida após o nascimento do bebê, $82,4 \%$ responderam que consideram que tem uma boa qualidade de vida e $17,6 \%$ responderam que não tem uma boa qualidade de vida após o nascimento do filho.

A falta de autonomia da mãe acaba comprometendo a garantia da amamentação de forma exclusiva pelo período recomendado. $\mathrm{O}$ estado mental das mães acaba afetando a sua produção de leite, fazendo com que introduzam complementos e outros acessórios como mamadeiras e chupetas (PEREIRA el al., 2021).

Avaliar as condições de vida de determinada população permite o desenvolvimento de práticas assistenciais e auxilia na definição de estratégias no contexto da promoção de saúde a partir de ações estruturadas. $O$ índice de qualidade de vida é um instrumento para gestão do cuidado que considera o indivíduo como um todo, em suas várias esferas, portanto mudanças ocorridas na saúde podem influenciá-la diretamente (CONDELES et al., 2019).

\subsection{CUIDADOS}

O comprometimento do cuidado com o recém-nascido exige uma alteração significativa na rotina da mulher, desde a privação de atividades corriqueiras até perda da sua autonomia. A literatura evidencia sentimentos como medo, irritação, insegurança e culpa gerado pela maternidade, que interferem diretamente na qualidade de vida da mulher (SCHUMACHER et al., 2020).

Sobre os cuidados, foi agrupado o autocuidado direcionado ao uso de contraceptivo e o cuidado com o bebê. Quando questionadas "atualmente você está utilizando algum anticoncepcional?" $58,8 \%$ responderam que sim e 41,2\% responderam que não. É um número consideravelmente alto, levando em consideração que são puérperas adolescentes e se não receberem as informações corretas e necessárias, poderão ter uma nova gestação em seguida.

O desenvolvimento de ações voltadas à saúde sexual e ao planejamento familiar deve ser trabalhado, e informações sobre métodos contraceptivos devem ter grande destaque na Atenção Primária a saúde para evitar outras gestações não desejáveis (PEREIRA et al., 2021). 
$\mathrm{Na}$ pergunta sobre conseguir cuidar do bebê sozinha, $70,6 \%$ responderam que cuidam dos seus bebês sozinhas e 29,4\% responderam que recebem apoio de alguém. Mas como foi citado no tópico família, $88,2 \%$ receberão ajuda de algum familiar no período do pós-parto, indicando suporte e contribuição de pessoas próximas.

O apoio social recebido pela mãe adolescente é fator determinante para o enfrentamento dessa etapa. A maneira como a adolescente vivencia o puerpério pode ser influenciada pelo apoio social que recebe. Este apoio contempla relações interpessoais correspondentes às funções emocional, informativa e instrumental, que dependem da disponibilidade e qualidade para influenciar no seu grau de satisfação (CREMONESE et al., 2017).

O apoio emocional está relacionado a sentimentos como afeto, amor, empatia e respeito; o aspecto informativo refere-se às sugestões, informações, conselhos e opiniões; o instrumental se refere ao auxílio financeiro, tempo dedicado e disponibilização de recursos, bens e serviços. Todos esses aspectos relacionam-se diretamente à condição e bem-estar da mãe no pós-parto (CREMONESE et al., 2017).

\section{CONCLUSÃO}

Este estudo contribui com o perfil sociodemográfico das puérperas em período da adolescência as quais residem na cidade de Ponta Grossa, Paraná.

Evidencia-se a necessidade da criação de abordagens personalizadas para gestantes adolescentes nas consultas de pré-natal, das quais devem incluir preocupações pessoais além das orientações fisiológicas da gestação.

O pré-natal, é o momento mais oportuno para esclarecer dúvidas e prestar às gestantes informações sobre diferentes temas, inclusive sobre amamentação. Portanto, é indispensável a execução de um excelente pré-natal, que não se limite ao básico e consiga envolver gestante, parceiro e a família nesse processo.

\section{REFERÊNCIAS}

ANDRADE, R. D., et al. Cuidado de enfermagem materno-infantil para mães adolescentes: educação em saúde. Revista Brasileira de Enfermagem , v. 73, 2020. Acesso em: 28 de nov. de 2020.

BARROS, K. R. S., et al. Perfil epidemiológico e conhecimento de gestantes sobre aleitamento materno em um município do nordeste brasileiro. Arq. ciências saúde UNIPAR, p. 11-17, 2021. Acesso em: 16 de out. de 2021. 
BRASIL. Ministério da Saúde. Saúde Da Criança Aleitamento Materno e Alimentação Complementar. $2^{a}$ edição Cadernos de Atenção Básica, no 23. Brasília, 2015. Acesso em: 17 de nov. de 2020.

CARPES, F.; BIFF, D.; STUMM, K.E. Percepção de acadêmicos de enfermagem acerca do papel do enfermeiro no cuidado pré-natal. Revista Enfermagem Atual In Derme, v. 79, n. 17, 2016. Acesso em: 01 de nov. de 2020.

CONDELES, P.C. et al. Qualidade importância e satisfação. Revista da Rede de Enfermagem do Nordeste, Fortaleza, v. 20, e41421, 2019. Acesso em: 10. de nov de 2020 .

CREMONESE, L. et al. Apoio social na perspectiva da puérpera adolescente. Escola Anna Nery, v. 21, 2017.Acesso em: 20 de nov. de 2020

CREMONESE, L. et al. O processo da amamentação na adolescência: vivências rememoradas por mulheres. Journal of Nursing UFPE/Revista de Enfermagem UFPE, v. 10, n. 9, 2016. Acesso em: 08 de nov. de 2020.

CREMONESE, L. et al. Vivências do período gravídico-puerperal na perspectiva de mulheres adolescentes. Rev. Pesqui.(Univ. Fed. Estado Rio J., Online), p. 1148-1154, 2019.Acesso em: 19 de nov. de 2020.

DUARTE, E. S.; PAMPLONA, T. Q.; RODRIGUES, A. L. A gravidez na adolescência e suas consequências biopsicossociais. De Ciência em FOCO, v. 2, n. 1, p. 45-52, 2018. Acesso em: 28 de nov. de 2020.

FARINHA, F. T. et al. Correlação entre espiritualidade, religiosidade e qualidade de vida de adolescentes. Revista Bioética , v. 26, p. 567-573, 2018.Acesso em: 16 de nov. de 2020

FERREIRA, H. L. O. C., et al. Fatores associados à adesão ao aleitamento materno exclusivo. Ciencia \& saude coletiva, v. 23, p. 683-690, 2018. Acesso em: 05 de nov. de 2020 .

LEITÃO, A. L. M.; BENEVIDES, M. G. Gravidez na adolescência: será realmente um problema?. Conhecer: debate entre o público e o privado, v. 6, n. 16, p. 05-24, 2016.Acesso em: 20 de nov. de 2020

MENEZES A.H.N; et al. Metodologia Científica: teoria e aplicação na educação à distância. Universidade Federal do Vale do São Francisco, Petrolina, PE, pág 29-30, 2019. Acesso em: 28 de nov. de 2020.

MONTEIRO, N. R. O. et al. Gravidez e maternidade de adolescentes: fatores de risco e de proteção. Journal of Human Growth and Development, v. 21, n. 2, p. 198-209, 2011. Acesso em: 10 de nov. de 2020. 
PEREIRA, A.O.R., et al. Fatores que interferem na realização do aleitamento materno exclusivo. Nursing (São Paulo), v. 24, n. 274, p. 5401-5418, 2021. Acesso em: 15 de out. de 2021.

RODRIGUES, M.P. et al. Percepções sobre os efeitos psicossociais da gravidez na adolescência no cenário da Estratégia Saúde da Família. Revista Ciência Plural, v. 3, n. 1, p. 81-97, 2017.Acesso em: 28 de nov. de 2020.

SANTOS, N. L. B.; GUIMARÃES, D. A.; DA GAMA, C. A. P. A percepção de mães adolescentes sobre seu processo de gravidez. Revista Psicologia e Saúde, v. 8, n. 2, p. 83-96, 2016.Acesso em: 20 de nov. de 2020

SCHUMACHER, L. M. et al. Relação da qualidade de vida com dados sociodemográficos e nutricionais de gestantes e puérperas. Revista Brasileira em Promoção da Saúde, v. 33, 2020.Acesso em: 28 de nov. de 2020.

Recebido em: 15/10/2021

Aprovado em: 10/11/2021

Publicado em: 12/11/2021 